\begin{tabular}{|c|c|c|}
\hline $\begin{array}{l}\text { PKS } \\
\text { PUBLIC } \\
\text { KNDOLEDGE } \\
\text { PROJECT }\end{array}$ & $\begin{array}{c}\text { REVISTA DE GEOGRAFIA } \\
\text { (RECIFE) } \\
\text { http://www.revista.ufpe.br/revistageografia }\end{array}$ & $\frac{\text { OJS }}{\text { OPEN }}$ \\
\hline
\end{tabular}

\title{
ANÁLISE DA DISTRIBUIÇÃO TERRITORIAL DOS EMPREENDIMENTOS COM EIAS/RIMAs NO ESTADO DA PARAÍBA NOS ANOS DE 2003 A 2014
}

\author{
Valdeniza Delmodes Pereira1 ${ }^{1}$ Henrique Elias Pessoa Gutierres²
}

\author{
${ }^{\prime}$ Geógrafa (UFPB) e Técnica em Meio Ambiente (IFPB).E-mail: del_mondes@hotmail.com \\ ${ }^{2}$ Geógrafo do Departamento de Geociências (UFPB) e Doutorando do Programa de Pós-Graduação em \\ Geografia (PPGEO/UFPE).E-mail: hepg86@hotmail.com
}

Artigo recebido em 27/07/2017 e aceito em 10/05/20187

\begin{abstract}
RESUMO
O Estudo de Impacto Ambiental e o seu respectivo Relatório de Impacto Ambiental (EIA/RIMA) estão previstos na legislação ambiental brasileira objetivando subsidiar o licenciamento ambiental de empreendimentos públicos e privados com significativo poder de degradação ambiental. Para a ciência geográfica é fundamental fazer uma análise regional/territorial de como essas atividades econômicas buscam as suas áreas de atuação e exercem influência na organização e na dinâmica territorial do território paraibano, afetando os componentes dos meios físico, biológico e antrópico, consumindo e produzindo espaços. Este trabalho realiza uma abordagem geográfica dos EIAs/RIMAs no estado da Paraíba, analisando a distribuição geográfica dos empreendimentos que demandaram apresentar o EIA/RIMA, entre os anos de 2003 a 2014. Trata-se de uma pesquisa descritiva documental, cujo objeto de estudo foram os EIAs/RIMAs para fins de licenciamento ambiental, que foram levantados junto ao setor de documentação do órgão estadual de meio ambiente da Paraíba. A partir da caracterização dos empreendimentos, constata-se que as regiões de maior desenvolvimento econômico e de maior densidade demográfica apresentaram o maior número de empreendimentos sujeitos ao licenciamento ambiental com EIA/RIMA, o que evidencia a prática da seletividade espacial na produção de novos espaços.

Palavras-chave: EIA/RIMA; Paraíba; Análise regional/territorial.
\end{abstract}

\section{ANALYSIS OF THE TERRITORIAL DISTRIBUTION OF THE ENTERPRISES WITH EIAs / RIMAS IN THE STATE OF PARAÍBA IN THE YEARS OF 2003 TO 2014}

\begin{abstract}
The Environmental Impact Study and its respective Environmental Impact Report (EIA/RIMA) are foreseen in Brazilian environmental legislation aimed at subsidizing the environmental licensing of public and private enterprises with significant environmental degradation. For geographic science it is fundamental to make a regional / territorial analysis of how these economic activities seek their areas of influence and influence the organization and territorial dynamics of the territory of Paraiba, affecting the components of the physical, biological and anthropic means, consuming and producing spaces. This work presents a geographical approach to EIAs / RIMAs in the state of Paraíba, analyzing the geographic distribution of the projects that demanded to present the EIA / RIMA between 2003 and 2014. This is a descriptive documentary research whose object of study were EIAs / RIMAs for environmental licensing purposes, which were collected from the documentation section of the state environmental agency of Paraíba. Based on the characterization of the projects, it can be seen that the regions with greater economic development and greater population density presented the highest number of projects subject to environmental licensing with EIA / RIMA, which shows the practice of spatial selectivity in the production of new spaces.
\end{abstract}

Keywords: EIA / RIMA; Paraíba; Regional/territorial analysis. 


\section{INTRODUÇÃO}

O processo de desenvolvimento sustentável implica em um processo de mudanças radicais, onde se espera que a exploração dos recursos naturais, a direção dos investimentos, a orientação tecnológica e as mudanças institucionais articulem-se de forma a atender às necessidades sociais e aspirações humanas das gerações presentes e futuras (CARVALHO, 2003). A participação popular na luta por um desenvolvimento sustentável foi de grande importância para que muitas transformações ocorressem no campo ambiental. Os movimentos ambientalistas, na década de 1970, exerceram grande pressão sobre os governos, contribuindo para que muitas mudanças ocorressem, a exemplo da National Environmental Policy Act (NEPA), Política Nacional de Meio Ambiente dos Estados Unidos, que foi formulada graças à pressão feita aos órgãos ambientais federais, por grupos de ambientalistas, pacifistas e defensores dos direitos humanos, que receberam apoio da sociedade e do Poder Legislativo (RIBEIRO, 2004), servindo de modelo para a implantação de políticas ambientais em diversos países.

No Brasil, a década de 1970 foi marcada pela entrada de grandes projetos no país. E para atrair o desenvolvimento, o ministro Costa Cavalcante, do governo Médici, declarou na Conferência de Estocolmo em 1972 que "a pior poluição é a pobreza, mas nós queremos poluição porque queremos desenvolvimento" (TEIXEIRA ET AL. 2006, p. 167). No entanto, o país teve que mudar essa postura em virtude das pressões dos organismos financiadores, que exigiam que a questão ambiental fosse inserida na análise da viabilidade dos grandes projetos (TEIXEIRA ET AL., 2006). De acordo com Sanchez (2013), tanto fatores externos quanto internos proporcionaram o avanço das políticas ambientais no Brasil, levando o Poder Executivo a promulgar a lei que trata da Política Nacional de Meio Ambiente (Lei Federal no 6.938, de 31 de agosto de 1981). Com o propósito de prevenir e minimizar os danos ambientais causados pelos grandes empreendimentos é que se implementou no Brasil, e em outros países, a obrigatoriedade da elaboração de estudos ambientais, dentre eles o Estudo de Impacto Ambiental (EIA) e o seu respectivo Relatório de Impacto Ambiental (RIMA), exigidos para o licenciamento ambiental de atividades efetiva ou potencialmente causadoras de significativa degradação do meio ambiente, conforme previsto no artigo 225 da Constituição Federal de 1988.

A abordagem regional presente neste trabalho reflete o entendimento da pluralidade presente no espaço geográfico paraibano, estando este subdivido em mesorregiões, caracterizadas por suas particularidades físicas, biológicas, sociais, econômicas e culturais. As 
regiões, conforme entende Santos (2002), representam o suporte e a condição de relações globais. Sendo assim, as mudanças ocorridas no espaço geográfico podem ser positivas ou negativas, especialmente no que se refere à instalação de empreendimentos com significativa capacidade de degradação ambiental, pois, os impactos negativos gerados pela construção e/ou operação de um empreendimento podem gerar problemas com repercussões nos componentes naturais (abióticos e bióticos), em aspectos econômicos e no meio social.

No interesse de conhecer a configuração geográfica do licenciamento ambiental dos empreendimentos/atividades (públicos e privados) que demandaram a elaboração de EIA/RIMA no estado da Paraíba, localizado na região nordeste do Brasil, este trabalho tem o objetivo de discutir a distribuição geográfica dos empreendimentos que protocolaram o EIA/RIMA no órgão ambiental estadual, entre os anos de 2003 e 2014, por meio de uma abordagem territorial/regional. Constitui uma contribuição para os estudos de análise regional, territorial e ambiental no Nordeste brasileiro, a partir de dois instrumentos demandados pelo poder público, previstos na Política Nacional de Meio Ambiente.

\section{Licenciamento Ambiental}

A Lei da Política Nacional de Meio Ambiente, no seu artigo 9º expõe vários instrumentos a serem implementados, dentre os quais se destaca o inciso IV: "o licenciamento e a revisão de atividades efetiva ou potencialmente poluidoras". De acordo com a definição da Resolução do CONAMA no 237 (BRASIL, 1997), o licenciamento ambiental é um procedimento administrativo pelo qual o órgão ambiental competente licencia a localização, instalação, ampliação e a operação de empreendimentos e atividades utilizadoras de recursos ambientais, consideradas efetiva ou potencialmente poluidoras ou daquelas que, sob qualquer forma, possam causar degradação ambiental, considerando as disposições legais e regulamentares e as normas técnicas aplicáveis ao caso. Em se tratando de um procedimento, o licenciamento ambiental se divide em três etapas básicas (planejamento, instalação e operação), sendo as licenças ambientais expedidas de acordo com a fase em que se encontra o empreendimento ou atividade. O artigo $8^{\circ}$ da Resolução CONAMA no 237 (BRASIL, 1997) determina que o poder público, no exercício de sua competência de controle, expedirá as licenças: Prévia (LP), de Instalação (LI) e de Operação (LO). Vale destacar que não são todas as atividades e empreendimentos que estão sujeitos ao licenciamento ambiental. A relação de algumas das atividades ou empreendimentos sujeitos ao licenciamento ambiental encontra-se 
no anexo I da Resolução CONAMA no 237 (BRASIL,1997), não sendo uma lista exaustiva, cabendo ao órgão ambiental competente "definir os critérios de exigibilidade, o detalhamento e a complementação dessa relação, considerando as especificidades, os riscos ambientais, o porte e outras características do empreendimento ou atividade” (BARBIERI, 2007, p. 293).

O licenciamento ambiental representa o mecanismo através do qual o poder público busca controlar as atividades econômicas que degradam ou possam degradar o meio ambiente, através da permissão para que um empreendimento seja instalado e venha a operar. Porém, tal instrumento contempla desde empreendimentos de menor porte (a exemplo de restaurantes, padarias, lava-jatos etc.) até empreendimentos de grande porte e com alto poder degradador (mineração, aterros sanitários, aeroportos, projetos urbanísticos etc.). Para estes empreendimentos, a legislação impõe a obrigação de que o licenciamento ambiental seja acompanhado do Estudo de Impacto Ambiental (EIA), que é um dos estudos ambientais possíveis de serem solicitados pelos órgãos ambientais (federal, estaduais ou municipais). Contudo, nem todos os empreendimentos/atividades são capazes de causar impactos ambientais significativos, e, portanto, a legislação possibilita a exigência de estudos ambientais simplificados (Relatório Ambiental Simplificado - RAS; Estudo de Viabilidade Ambiental - EVA), que não possuem a profundidade e a complexidade do EIA/RIMA.

\section{Estudo de Impacto Ambiental}

De acordo com Hooke (1988), a legislação ambiental já vinha exigindo a elaboração e a apresentação dos EIAs há algumas décadas em vários países, com destaque para os Estados Unidos e em alguns países europeus.

A Lei Federal $n^{\circ}$ 6.803/80, que trata do zoneamento industrial, foi responsável pela introdução do termo EIA no Brasil, porém ainda sem critérios e definições. Portanto, tal estudo só passa a ser incorporado efetivamente à legislação brasileira com a Lei Federal $n^{\circ}$ 6.938/81 (Política Nacional do Meio Ambiente), tornando-o parte integrante do processo de licenciamento de atividades e empreendimentos efetiva ou potencialmente poluidores ou causadores de degradação ambiental. Posteriormente, o Conselho Nacional de Meio Ambiente (CONAMA) aprovou e publicou a Resolução $n^{\circ}$ 01/86, que elenca uma série de diretrizes voltadas para a elaboração do EIA/RIMA. O EIA é um instrumento que proporciona a prevenção e a avaliação dos impactos ambientais de um empreendimento ou atividade sobre os meios físico, biológico e socioeconômico, identificando mecanismos para evitá-los antes que o empreendimento seja implantado, permitindo a participação popular e de outros órgãos

Pereira e Gutierres, $2018 \quad$ ISSN 0104-5490 180


públicos (BARBIERI, 2007). Percebe-se que é um importante instrumento de proteção ambiental, não podendo se resumir, como afirmam Milaré e Benjamin (1993), em uma "mera ferramenta procedimental", e tem como objetivo central a prevenção do dano ambiental, representando um importante meio de aplicação de uma política preventiva, sendo, portanto, um documento de subsídio ao licenciamento ambiental. E, sendo guiado por estudos mal elaborados, mascarando impactos importantes, o órgão ambiental poderá aprovar e licenciar empreendimentos que causarão danos sérios e irreversíveis ao ambiente. Mas, em alguns casos, verifica-se que o EIA/RIMA é elaborado e protocolado no órgão ambiental como uma 'prática cartorial', voltada ao cumprimento da exigência legal, mas sem o aprofundamento da análise do conteúdo do material entregue, o que não contribui para subsidiar a tomada de decisão sobre a viabilidade do empreendimento ou atividade. Prova disso são as publicações de autores (BRASIL - MPF, 2004; PAES, 2010; SÁNCHEZ, 2013; PEREIRA, 2015; GUTIERRES ET AL., 2017), que demonstraram diversas deficiências nos estudos analisados.

Na sua estruturação mínima, conforme determina a Resolução CONAMA nº 01/86, o Estudo de Impacto Ambiental (EIA) deve conter os seguintes conteúdos: I- Diagnóstico ambiental, considerando: o meio físico (geologia, geomorfologia, pedologia, clima, recursos hídricos etc.); o meio biológico e os ecossistemas naturais (fauna e flora); e o meio socioeconômico (uso e ocupação do solo, dinâmica populacional, atividades econômicas, infraestrutura, patrimônio histórico, cultural e arqueológico etc.); II- Análise e identificação dos impactos ambientais; III- Definição das medidas mitigadoras para os impactos negativos e IV- Elaboração do programa de acompanhamento dos impactos negativos e positivos.

Quanto ao RIMA, este deverá refletir as conclusões do estudo de impacto ambiental, devendo ser apresentado de forma objetiva e adequada à sua compreensão por parte do público leigo (SANCHEZ, 2013). Em sendo um instrumento para subsidiar a tomada de decisão pelo poder público, o EIA/RIMA envolve diversos atores: empreendedor (público ou privado), órgão ambiental licenciador (tomador de decisão), equipe elaboradora do EIA, entidades civis, outros órgãos públicos interessados e a sociedade em geral. Diante dos diversos conteúdos listados, percebe-se que o EIA deve ser entendido como uma etapa integrante do próprio projeto da obra ou da atividade potencialmente causadora de degradações significativas ao meio ambiente, que se insere num contexto territorial e regional a ser desvendado nos estudos geográficos. 
Análise territorial/regional, dinâmica econômica e espacial de empreendimentos

O conceito de região está relacionado à noção fundamental de diferenciação de área (CORRÊA, 2007). Dentro da ciência geográfica são apresentadas diversas abordagens conceituais resultantes dos diferentes paradigmas. Para Dantas e Moraes (2012, p.191), "processos de adaptações, reformulações e novos conceitos estão sintonizados com o quadro de mudanças teórico-metodológicas que a dinâmica espacial exige". Ao longo da evolução do pensamento geográfico constatam-se as fases no tocante a construção, destruição e reconstrução deste conceito (HAESBAERT, 2005). Santos (2002) compreende tal categoria de análise geográfica como suporte e condição para as relações globais.

Sobre a questão regional no Brasil, o Instituto Brasileiro de Geografia e Estatística (IBGE) é referência nesta abordagem e na evolução do uso das aplicações do conceito. Em especial, no ano de 1990, o IBGE realizou uma nova divisão regional, substituindo as Microrregiões Homogêneas pelas Mesorregiões e Microrregiões Geográficas (IBGE, 1990). Entende-se por mesorregião uma área individualizada em uma Unidade da Federação que apresenta formas de organização do espaço geográfico definidas pelas seguintes dimensões: o processo social como determinante, o quadro natural como condicionante e a rede de comunicação e de lugares como elemento da articulação espacial (IBGE, 1990). Cada Mesorregião é formada por um grupo de microrregiões. E estas são formadas por municípios que apresentam especificidades quanto à organização do espaço. Essas especificidades referem-se à estrutura de produção agropecuária, industrial, extrativismo mineral ou pesca (IBGE, 1990). Cada Mesorregião se distingue por suas características naturais, culturais e econômicas, o que confere a cada uma, dinâmicas próprias, mas que não as tornam isoladas, ao contrário, encontram-se integradas num amplo sistema de relações e de trocas entre si. $\mathrm{O}$ estado da Paraíba foi dividido em quatro mesorregiões: Mata Paraibana; Agreste Paraibano; Borborema e Sertão Paraibano.

Entende-se que o desenvolvimento capitalista de produção vem afetando e acarretando numa diferenciação no território nacional, com determinadas áreas passando por mudanças institucionais e avanços socioeconômicos, enquanto que outras passaram a um quadro de "estabilidade" ou apresentam problemas acentuados. Reconhecia-se o papel das condições naturais na orientação das formas de ocupação e produção agrárias, bem como identificavamse os processos de metropolização e industrialização como elementos estruturadores do espaço (MAGNAGO, 1995, p. 85 APUD ROCHA E OLIVEIRA, 2011, p. 12). O crescimento econômico, condição necessária para o desenvolvimento, não acontece de maneira uniforme 
por todo o território de um país ou de uma região. Sendo assim, "os processos socioespaciais são geograficamente localizados: crescente reorganização e rediferenciação no território, que se dão pelo movimento contínuo de relocalização das atividades produtivas e redistribuição espacial da população" (LIMONAD, 2007, p.146). A localização e (re)localização das indústrias no território não ocorrem de forma homogênea em todos os lugares, pois há a seletividade espacial, baseada em incentivos e amenidades dos locais.

Para a ciência geográfica é fundamental estudar como as atividades econômicas exercem influência na organização e na dinâmica territorial de uma determinada região, já que afetam os meios físico, biológico e antrópico, consumindo e produzindo espaços, conforme as palavras de Correa (1992, p.115): "a gestão do território constitui uma faceta da gestão econômica, política e social [...]. É a dimensão espacial do processo geral de gestão, confinando o espaço sob o controle de um estado, empresa ou grupo social". E acrescenta que "como qualquer outro fato social a gestão do território possui uma historicidade que se traduz em agentes sociais e práticas espaciais historicamente variáveis" (CORREA, 1992, p.115).

As práticas espaciais desenvolvidas pelas corporações são as estratégias usadas para a gestão do território. Corrêa (1992) elenca cinco práticas de poder frequentes das corporações sobre o espaço: seletividade espacial, fragmentação/remembramento espacial, antecipação espacial, marginalização espacial e reprodução da região produtora. $\mathrm{O}$ autor destaca que tais práticas não são mutuamente excludentes e podem ocorrer de forma combinada. Das práticas citadas, entende-se que a seletividade espacial, inicialmente, expressa relação direta com a distribuição geográfica dos EIAs/RIMAs num determinado território, já que os empreendimentos irão buscar se instalar em áreas que permitam a proximidade com a matéria prima, acesso ao mercado consumidor final, fontes de energia, presença de um porto, vantagens fiscais, infraestrutura pronta, dentre outros fatores.

Diante da diversidade de ramos de atividades a serem abordados neste trabalho, é possível constatar que tais fatores se aplicam em maior intensidade a determinados empreendimentos, como no caso da mineração, que necessita, na maioria das vezes, como forma de maximizar os lucros, que os empreendimentos estejam situados junto as jazidas a serem exploradas. 


\section{METODOLOGIA}

O trabalho caracteriza-se por ser uma pesquisa descritiva-documental, que tem por objetos de estudo, os Estudos de Impacto Ambiental (EIAs) e os seus respectivos Relatórios de Impacto Ambiental (RIMAs), documentos arquivados e disponíveis para consulta no Centro de Documentação do órgão ambiental do estado da Paraíba (Superintendência de Administração do Meio Ambiente - SUDEMA), responsável pela maior parte do licenciamento ambiental na Paraíba. O recorte temporal da pesquisa é de 2003 a 2014, contemplando todos os ramos de atividade, tanto de iniciativa do poder público como do setor privado. Justifica-se a escolha por tal recorte temporal com o intuito de obter uma amostra mais significativa dos empreendimentos que apresentaram o EIA/RIMA.

Os dados foram transcritos no Excel e utilizados para a elaboração das tabelas e dos gráficos. Os mapas foram elaborados a partir da base cartográfica da Agência Executiva de Gestão das Águas do Estado da Paraíba (AESA), utilizando-se o Google Earth. Por meio deste foram localizados os empreendimentos nos municípios declarados nos Estudos de Impacto Ambiental. A partir da espacialização dos empreendimentos foi possível discutir a concentração, escassez ou falta de empreendimentos nas mesorregiões e nas microrregiões paraibanas, correlacionando com o referencial teórico do trabalho (livros, artigos em periódicos científicos, legislação ambiental - leis, resoluções etc., trabalhos acadêmicos e bases de dados de órgãos públicos).

\section{RESULTADOS}

No recorte temporal foram identificados e analisados trinta e quatro empreendimentos que necessitaram apresentar o EIA/RIMA para fins do licenciamento ambiental de suas atividades. A figura 1 mostra o total de EIAs/RIMAs protocolados na SUDEMA entre os anos de 2003 e 2014.

Figura 1: Total de EIAs/RIMAs protocolados na SUDEMA entre os anos de 2003 e 2014.

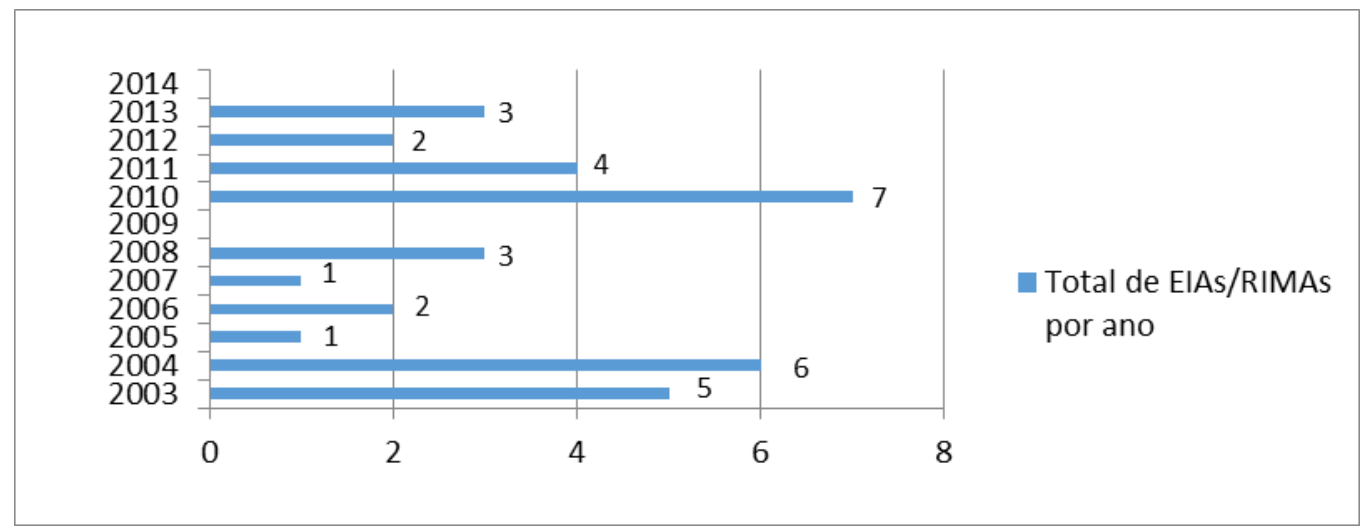

Fonte: Centro de Documentação da SUDEMA (Org.: Autores). 
O ano que apresentou o maior número de EIAs/RIMAs foi o ano de $2010 \mathrm{com}$ sete estudos, seguido dos anos de 2004 com seis EIAs e de 2003 com cinco estudos. Enquanto que os anos de 2009 e 2014 não registraram nenhum EIA protocolado no órgão ambiental.

Como se observa na figura 2, a quantidade de empreendimentos privados supera a dos empreendimentos públicos.

Figura 2: Total de EIAs/RIMAs protocolados na SUDEMA por iniciativa do poder público e do setor privado.

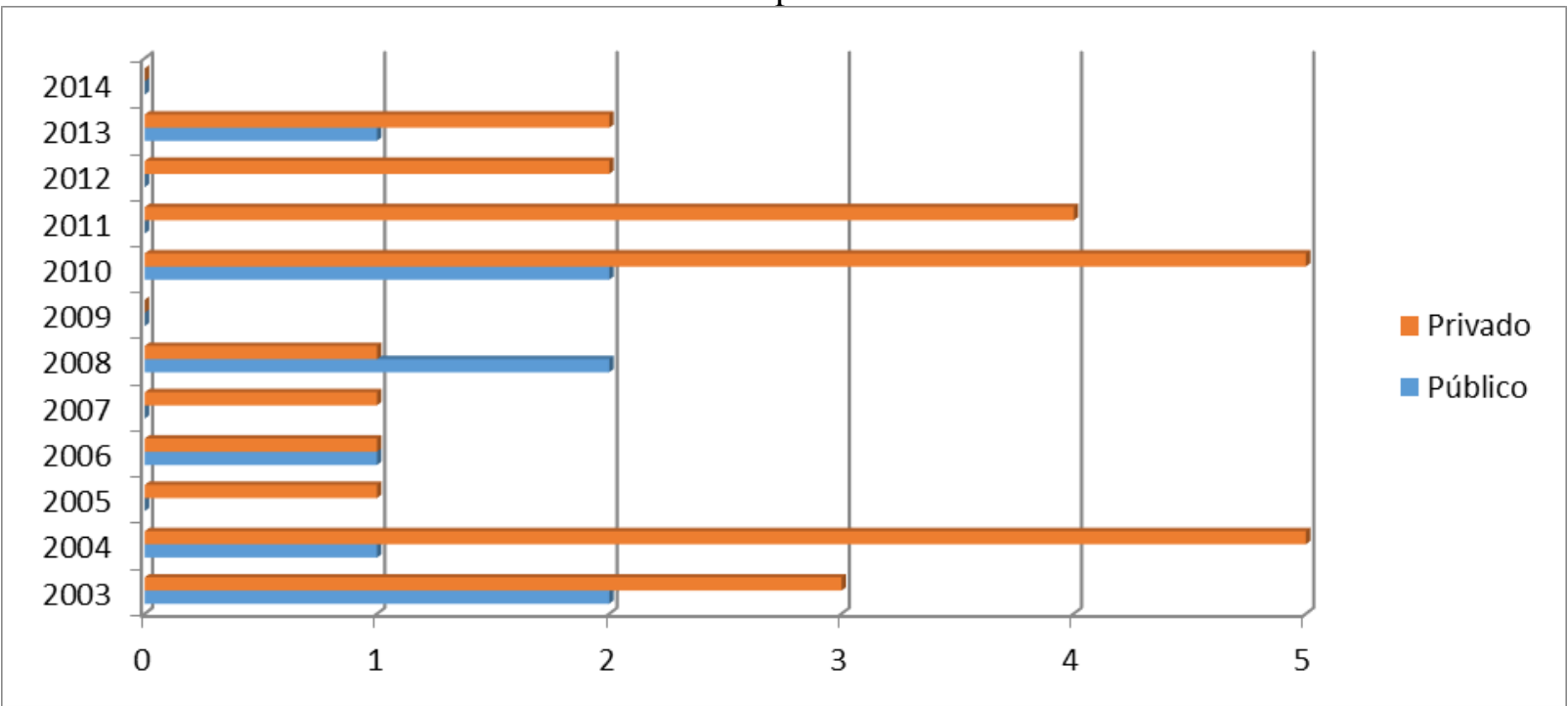

Fonte: Centro de Documentação da SUDEMA (Org.: Autores).

No ano de 2003 foram protocolados 3 (três) EIAs de empreendimentos privados e 2 (dois) públicos. Em 2004 há ainda um aumento de empreendimentos privados, totalizando 5 (cinco), contra apenas 1 (um) empreendimento público. No ano de 2006 se observa apenas 1 (um) empreendimento público e 1 (um) privado, já em 2010 foram 5 (cinco) privados e 2 (dois) públicos. No ano de 2008 foram protocolados 2 (dois) EIAs/RIMAs de empreendimentos públicos e apenas 1 (um) de empreendimento privado. Este foi o único ano em que o número de empreendimentos públicos superou o total de empreendimentos privados. Já nos anos de 2005, 2007, 2011 e 2012 só foram protocolados EIAs/RIMAs de empreendimentos privados.

Em termos percentuais, os privados totalizaram $74 \%$ dos empreendimentos analisados no referido período, compreendendo Hotéis, Resorts, Indústrias, Condomínios horizontais, Termelétricas, Shopping Center, dentre outros. Os empreendimentos públicos, que representaram $26 \%$, contemplaram obras e atividades de interesse social e de utilidade pública, como: Projeto de Regeneração da Praia do Cabo Branco; Aterros Sanitários (João 
Pessoa, Campina Grande, Puxinanã e Patos); Obras hídricas (Integração das águas da vertente litorânea; Barragem de Cupissura); Estação Ciência, Cultura e Arte; Urbanização da orla da cidade de Cabedelo, dentre outros (Figura 3).

Figura 3 - Tipologias dos empreendimentos dos EIAs/RIMAs analisados entre os anos de 2003 e 2014.

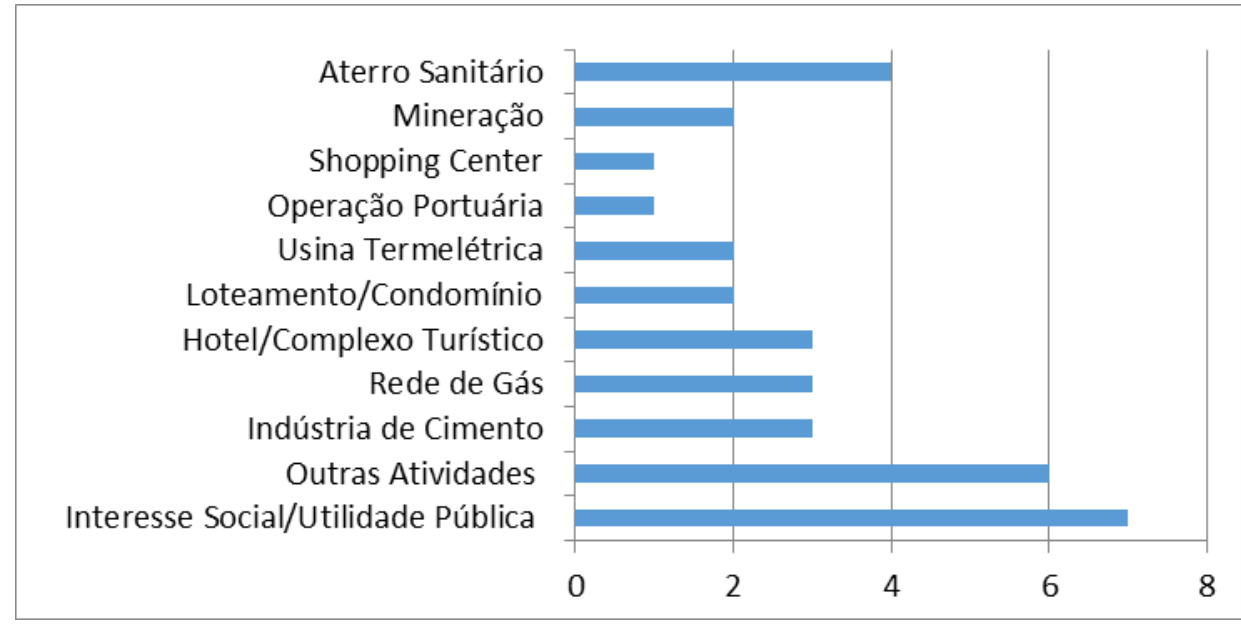

Fonte: Centro de Documentação da SUDEMA (Org.: Autores).

\section{DISCUSSÃO}

Com os dados apresentados no item anterior, o questionamento que fica seria: onde estariam localizados esses empreendimentos e quais as relações que podem ser compreendidas a partir dessa espacialização? Buscando um raciocínio geográfico para os dados coletados, tratados e sistematizados, estes permitem afirmar que as particularidades presentes no espaço geográfico paraibano influenciam na localização dos grandes empreendimentos - entendendo-se como grandes empreendimentos, aqueles considerados potencialmente causadores de significativa degradação do meio ambiente - pois, para serem instalados, além de dependerem de uma série de exigências legais, outras questões também exercerão influência, conforme posto por Corrêa (1992) na questão da seletividade espacial. Sejam questões de ordem econômica - melhor escoamento da produção, incentivos fiscais, disponibilidade de mão-de-obra, etc. - ou de ordem operacional - onde existe matéria prima específica, ou em virtude da própria geologia/geomorfologia ser compatível com o tipo de empreendimento - bem como de ordem política - quando da instalação de obras públicas para o atendimento das necessidades da população. 
Tomando a divisão do estado da Paraíba em quatro mesorregiões geográficas (Mata Paraibana, Agreste Paraibano, Borborema e Sertão Paraibano), a figura 4 apresenta a distribuição espacial dos empreendimentos em seu território.

De acordo com o Censo de 2010 do Instituto Brasileiro de Geografia e Estatística (IBGE), a população do estado da Paraíba era de 3.762.618 milhões de habitantes, e com base nestes dados, 1.391 .798 milhão de habitantes estão concentrados na mesorregião da Mata Paraibana, o que representa $37 \%$ da população do estado.

Figura 4 - Distribuição espacial (por mesorregiões) dos empreendimentos que protocolaram EIA/RIMA para serem licenciados no estado da Paraíba, entre os anos de 2003 a 2014.

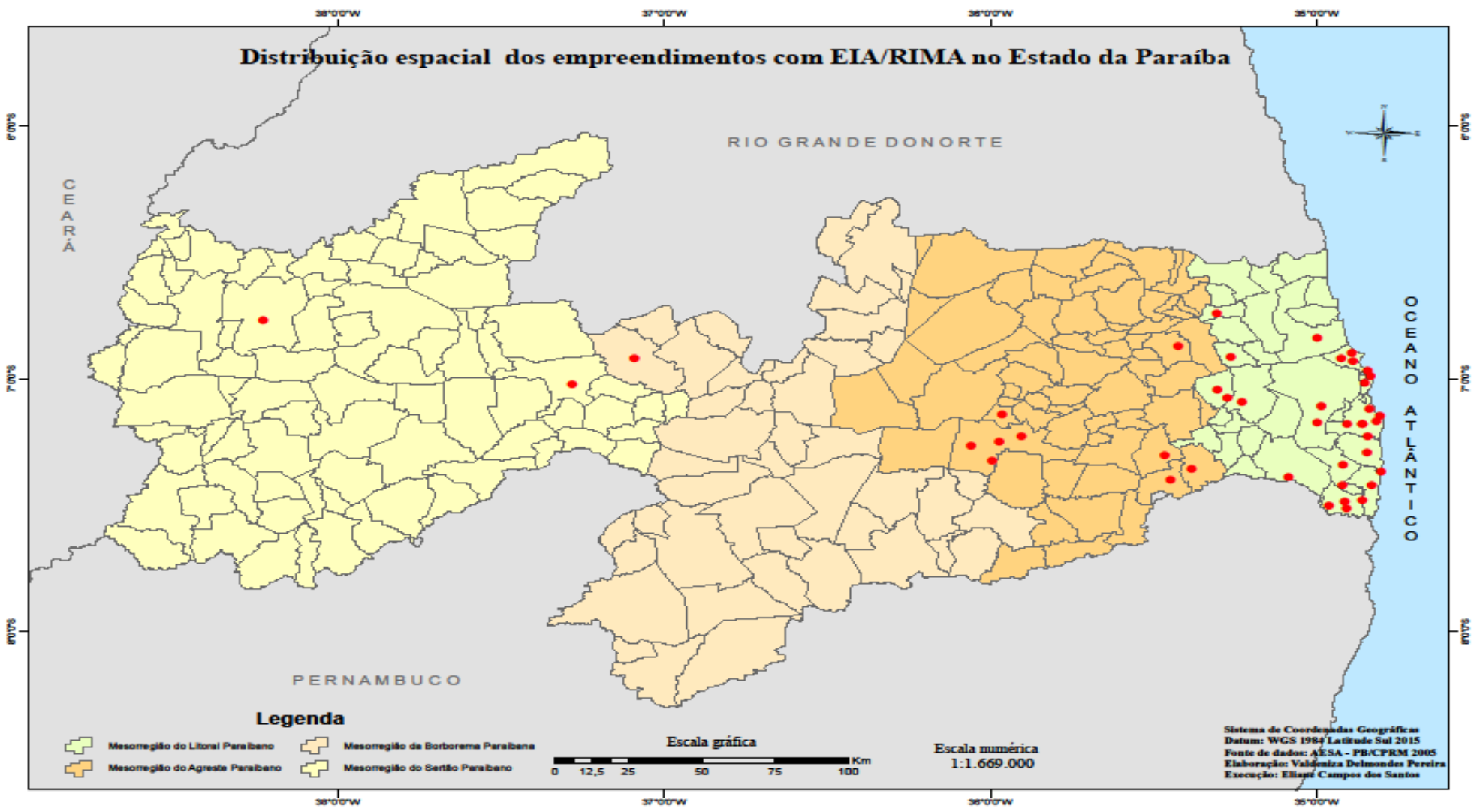

Portanto, é de se esperar a tendência de que os grandes empreendimentos estejam concentrados nessa mesorregião, especialmente, porque $70 \%$ correspondem a empreendimentos privados, que necessitam de grande mercado consumidor e fornecedor de mão-de-obra. Sendo assim, a mesorregião da Mata Paraibana concentra $79 \%$ dos empreendimentos/atividades que apresentaram o EIA/RIMA ao órgão ambiental estadual, $18 \%$ estão localizados na mesorregião do Agreste, $6 \%$ na mesorregião do Sertão e 3\% na mesorregião da Borborema. 


\section{Mesorregião da Mata Paraibana}

A Mesorregião da Mata Paraibana é composta por trinta municípios distribuídos por quatro microrregiões. Essa Mesorregião abrange 5.327,0 km², o que corresponde a 9,87\% do território estadual, estendendo-se da borda litorânea em direção ao interior.

A Mata Paraibana, tendo em vista diversos fatores, dentre os quais o maior contingente populacional concentrado, representa uma região com desenvolvimento econômico superior às demais mesorregiões. $\mathrm{O}$ crescimento econômico, condição necessária para o desenvolvimento, não acontece de maneira uniforme por todo o território de um país ou de uma região. Entende-se que “[...] manifesta-se com intensidades variáveis, em pontos ou pólos de crescimento; propaga-se, segundo vias diferentes e com efeitos finais variáveis, no conjunto da economia. $\mathrm{O}$ crescimento surge, preferencialmente, em alguns pontos do território de um país ou de uma região, os chamados "pólos de crescimento" (PERROUX, 1970, p.100, APUD, PERIS E LUGNANI, 2003, p. 80).

Dentro da perspectiva de "pólos de crescimento", compreende-se que a dispersão produtiva apresentou um considerável aumento decorrente do desenvolvimento das técnicas de informação e de comunicação. Isto certamente atrai a instalação de empreendimentos, especialmente os de grande porte, implicando em maiores trocas e fluxos entre os diversos setores que integram esse espaço. A partir dos dados obtidos é possível elencar duas particularidades que favorecem a concentração de empreendimentos nesta mesorregião: 1) Condições geológicas favoráveis à instalação de empreendimentos na área de mineração; 2) Região de maior adensamento populacional, tendo João Pessoa como cidade principal. Na figura 5 estão identificados os empreendimentos e atividades que demandaram EIA/RIMA para fins de licenciamento ambiental na Mesorregião da Mata.

Em virtude de suas características geológicas, essa é uma região rica em calcário e argila, matérias-primas essenciais para a fabricação de cimento e por esse motivo, a maior parte das indústrias cimenteiras estão localizadas no litoral sul. Considera-se também a existência das vias para recebimento e escoamento dos produtos, rodovias em melhores condições, além da maior rapidez no fluxo das mercadorias, estando assim inseridos em uma rede de trocas mais intensas entre as regiões vizinhas.

A outra característica que implica na maior concentração dos empreendimentos está no fato de ser uma região densamente povoada, cuja dinâmica está amplamente relacionada a um polo dominante, tendo João Pessoa como um grande centro irradiador da dinâmica regional em nível estadual. A Microrregião de João Pessoa abrange $74 \%$ da população da 
Mata Paraibana, concentrando 1.034.615 milhão de habitantes (IBGE 2010). Observa-se assim, a maior concentração dos empreendimentos nesta microrregião, formada pelos municípios de Bayeux, Cabedelo, Conde, João Pessoa, Lucena e Santa Rita (Figura 5).

Figura 5 - Mapa dos empreendimentos/atividades licenciados com EIA/RIMA, localizados na Mesorregião da Mata Paraibana.

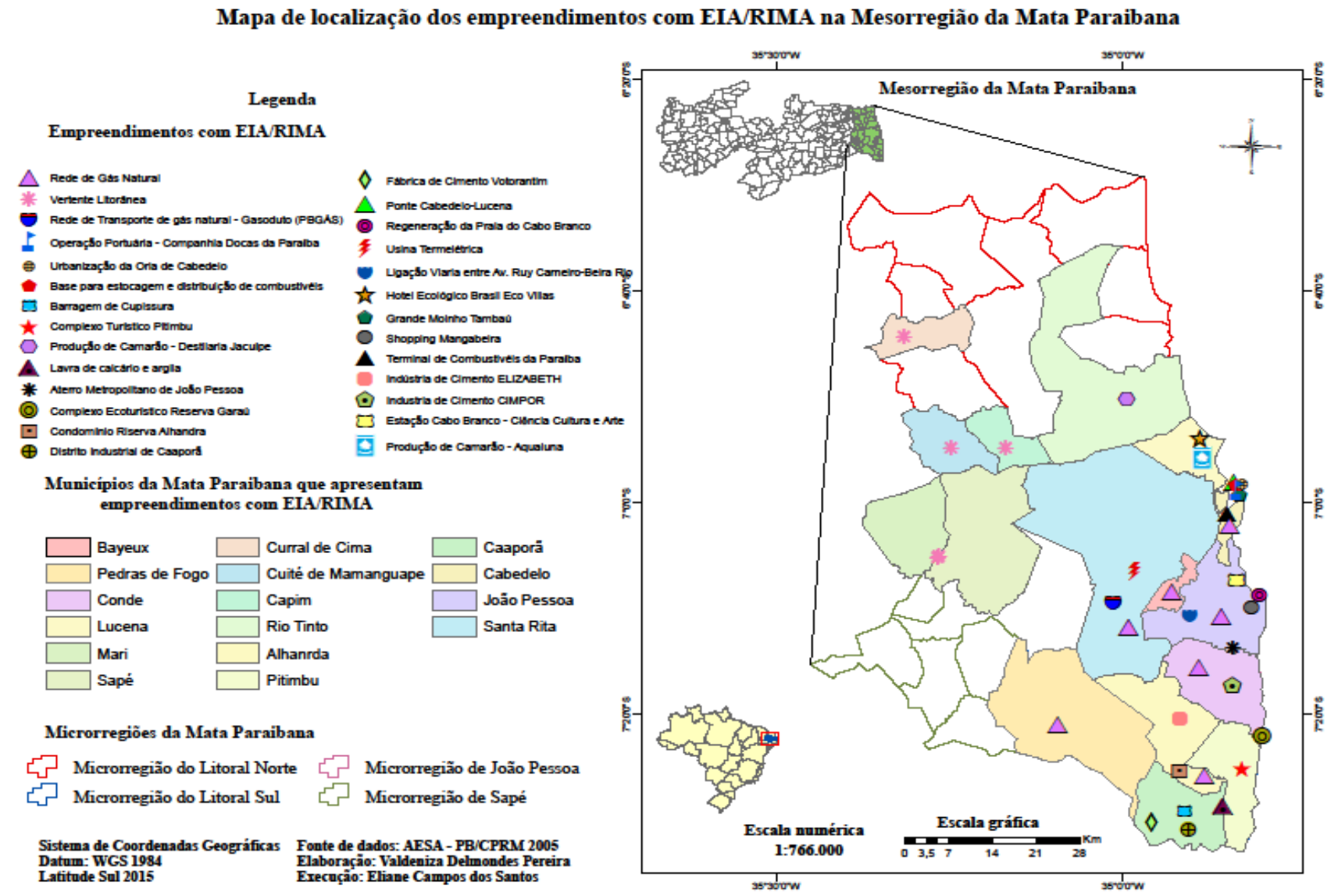

Desses empreendimentos, 66\% são privados e como exemplos de tipologias de empreendimentos, podem ser destacados: Aterro Sanitário; Rede de Gás Natural; Hotel Ecológico; Fazenda de Carcinicultura; Estação Ciência; Complexo Ecoturístico; Fábrica de Cimento; Shopping Center, dentre outros. Nessa microrregião observa-se também a presença do Porto de Cabedelo, que em virtude da dinâmica das operações realizadas, favorece a implantação de empreendimentos em suas proximidades, a exemplo das empresas TECOP Terminal de Combustíveis da Paraíba Ltda. e Grande Moinho Tambaú, que necessitaram apresentar EIA/RIMA para serem licenciadas, implicando em maior rapidez e menor custo no escoamento dos produtos.

A microrregião do Litoral Sul apresenta a segunda maior concentração de empreendimentos com 26\%. É uma região com forte potencial para o turismo e para a 
mineração. Observa-se a presença de empreendimentos e atividades, como: Lavra de calcário, Indústrias de cimento, Resort, Condomínio Residencial, entre outros. Além disso, destaca-se a implantação do Distrito Industrial de Caaporã, que sofrerá influência do Polo Industrial de Goiana-PE, acarretando numa nova dinâmica socioeconômica nessa região. Já as microrregiões do Litoral Norte e Sapé registraram 4\% dos empreendimentos, cada uma.

\section{Mesorregião do Agreste Paraibano}

A Mesorregião do Agreste Paraibano é composta por 66 municípios, distribuídos por oito microrregiões. Estende-se desde a retaguarda dos tabuleiros costeiros a leste, até o limite com a Mesorregião da Borborema. Possui uma área de $13.432 \mathrm{Km}^{2}$, correspondendo a 23,8\% do território estadual. Conforme o Censo do IBGE de 2010, a população da Mesorregião do Agreste Paraibano é de 1.213.279 milhão de habitantes, o que corresponde a $32 \%$ da população do Estado. Esta Mesorregião encontra-se numa situação intermediária entre o úmido e o semiárido. Sua individualidade está relacionada ao pluralismo, tanto no que se refere às condições naturais, quanto à organização das atividades econômicas. Na mesorregião do Agreste, embora exista um forte adensamento populacional, e tendo a cidade de Campina Grande como um importante centro de desenvolvimento regional, observou-se a presença de apenas seis empreendimentos com EIA/RIMA protocolados na SUDEMA (Figura 6), dos quais quatro são privados.

Figura 6 - Mapa dos empreendimentos/atividades licenciados com EIA/RIMA, localizados na Mesorregião do Agreste Paraibano.

Mapa de localização dos empreendimentos com EIA/RIMA na Mesorregião do Agreste Paraibano

Legenda

Empreendimentos com EIA/RIMA

- Rede de Distribuição de $22 \mathrm{Km}$ - Gasoduto.

3 Unidade Termelétrica

A Aterro Sanitário de Campina Grande

- Aterro Sanitário de Puxinanã

* Rede de Transporte de gás natural - Gasoduto (PBGÁS)

* Vertente Litorânea

Municípios do Agreste Paraibano que apresentam empreendimentos com EIA/RIMA

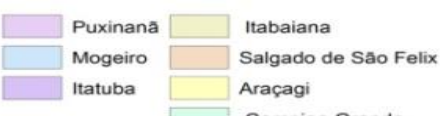

Itatuba

Microrregiōes do Agreste Paraibano

Microrregião de Campina Granc (2) Microrregiâo de Umbuzeiro ¿2 Microrregiâo de Esperança (5) Microrregiào de Guarabira

5. Microrregião do Curimataú Ocidental Microrregião do Curimataú Ocidenta L Microrregiâo de Itabaiana 고 Microrregião do Brejo Paraibano

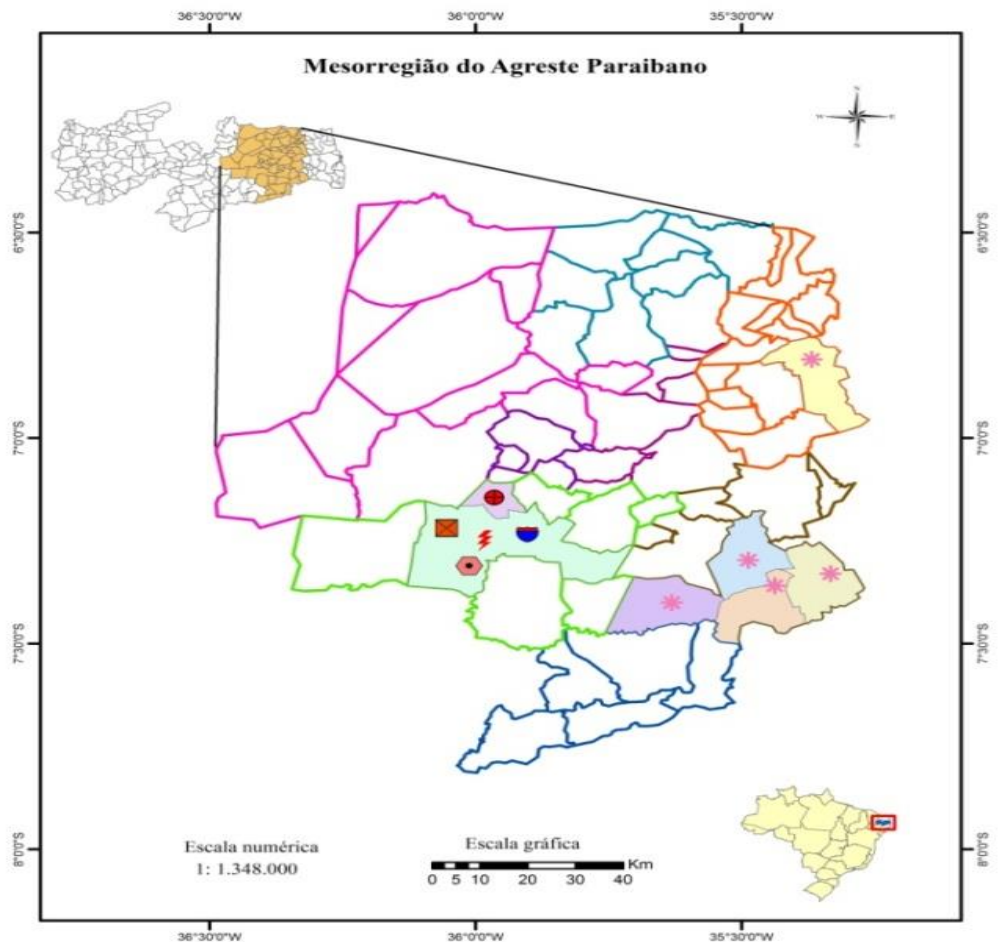


O segundo maior parque industrial do estado da Paraíba encontra-se no município de Campina Grande e representa um dos principais polos industriais da região Nordeste. Exceto o empreendimento "Vertente Litorânea", todos os demais empreendimentos estão localizados na microrregião de Campina Grande: Aterros Sanitários; Gasoduto; Termelétrica; e Rede de Gás Natural (PBGÁS). Os dois aterros sanitários licenciados com EIA/RIMA foram concebidos para receber os resíduos da cidade de Campina Grande e cidades vizinhas.

\section{Mesorregião da Borborema}

A Mesorregião da Borborema é composta por 44 municípios, distribuídos por quatro microrregiões. Está localizada entre o Sertão e o Agreste, compreendendo a porção central do compartimento geomorfológico do Planalto da Borborema, e abrange $16.013 \mathrm{~km}^{2}$, representando 28,3\% do território estadual. Possui uma população de 298.563 mil habitantes (IBGE, 2010), correspondendo a $8 \%$ da população estadual. É uma região bem individualizada tanto em relação às condições naturais, quanto no que se refere à estrutura produtiva. Nessa mesorregião são registrados os menores índices pluviométricos da Paraíba e se destaca por compreender a maior concentração de ocorrências minerais do território paraibano (FELICIANO E MELO, 2003). A figura 7 revela a presença de apenas um empreendimento, o que corresponde a 3\% dos empreendimentos que apresentaram EIA/RIMA no estado da Paraíba. O Seridó paraibano representa uma região rica em minérios e por essa razão a empresa Casa Grande Mineração cogitou se instalar nesta área, onde exerceria a atividade de "explotação de Talco e Minério de Ferro", no entanto, o empreendimento não chegou a ser instalado, pois o licenciamento ambiental foi indeferido pela SUDEMA.

Levando-se em consideração que $74 \%$ dos empreendimentos que apresentaram EIA/RIMA para serem licenciados na Paraíba são privados e devido ao alto custo para a implantação desses empreendimentos, a começar pelo custo de elaboração do EIA/RIMA, provavelmente as particularidades presentes nesta mesorregião desfavoreceram a implantação de grandes empreendimentos, tendo em vista que apresenta um meio físico com características adversas para algumas atividades econômicas, além de ser a de menor densidade populacional. Uma particularidade do Seridó paraibano está no fato da exploração dos minérios ser feita por pequenos mineradores, em sua grande maioria pessoas físicas que 
exploram essa atividade de forma rudimentar, pois são extraídos, na maioria das vezes, por meio de pequenas mineradoras e garimpos com o uso de métodos e instrumentos rústicos.

Figura 7 - Mapa da atividade licenciada com EIA/RIMA, localizada na Mesorregião da Borborema.

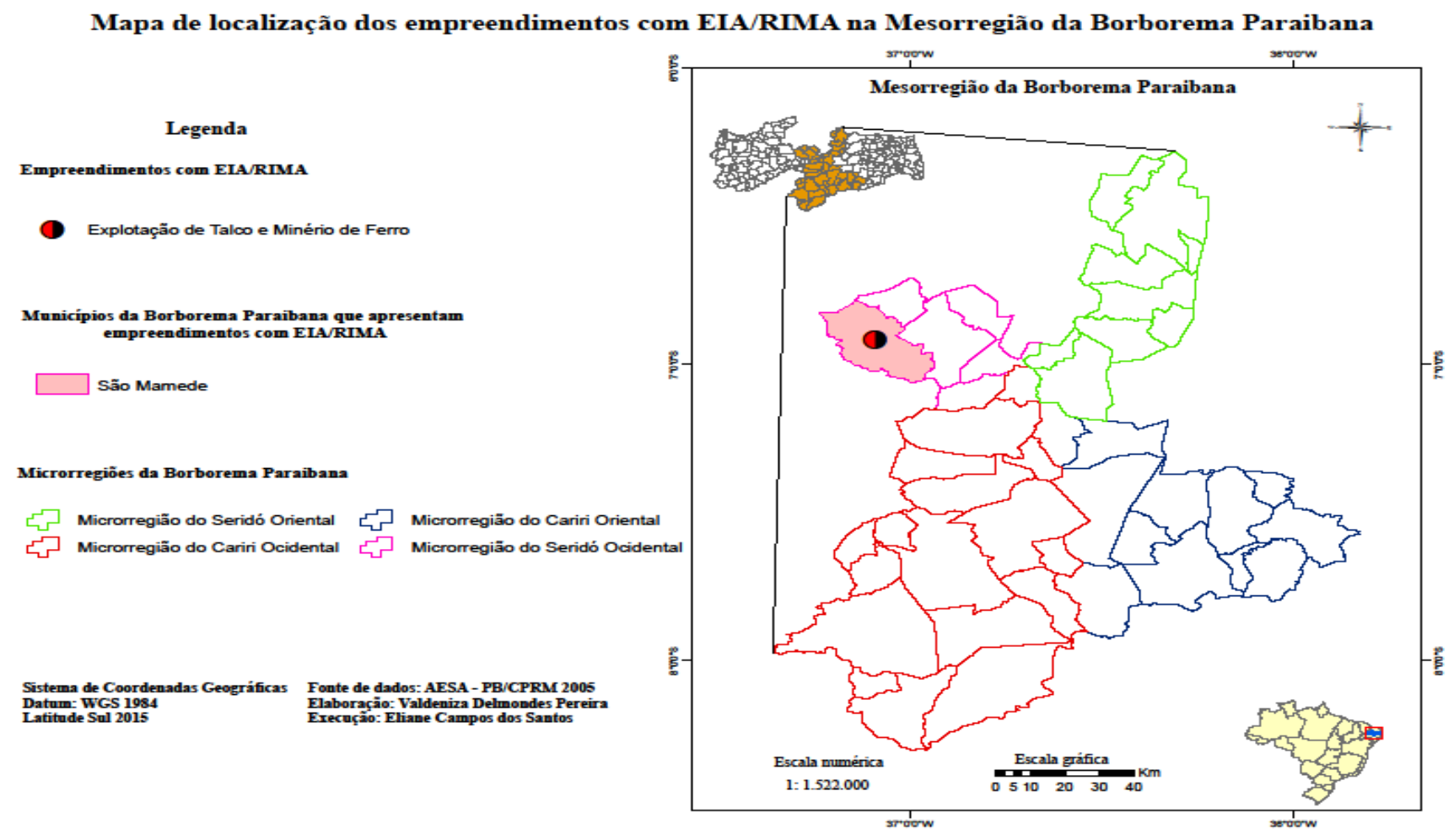

Mesorregião do Sertão Paraibano

A Mesorregião do Sertão é composta por 83 municípios, distribuídos por sete microrregiões. Abrange $22.466 \mathrm{Km}^{2}$, representando 39,8\% do território estadual. Esta mesorregião está situada à retaguarda da Borborema Central, estendendo-se pelo pediplano sertanejo e alcançando os alinhamentos das serras que fazem fronteira com os estados do Ceará, Rio Grande do Norte e Pernambuco. Encontra-se contida nos limites do clima semiárido e uma cobertura vegetal de caatinga (FELICIANO E MELO, 2003). Possui uma população de 858.978 mil habitantes, equivalente a $23 \%$ da população estadual, segundo o IBGE (2010).

O município de Patos se destaca como um polo de atração e de desenvolvimento dessa região, apresentando um distrito industrial expressivo em nível estadual. Durante o período analisado foram identificados apenas dois empreendimentos que protocolaram EIA/RIMA para serem licenciados nessa mesorregião, conforme demonstrado na figura 8 . Dentre as quatro Mesorregiões paraibanas, a Mesorregião do Sertão é a que possui o maior número de 
municípios, equivalente a $37 \%$ dos municípios que compõem o Estado, mas em termos populacionais ocupa o terceiro lugar.

Figura 8 - Mapa dos empreendimentos/atividades licenciados com EIA/RIMA, localizados na Mesorregião do Sertão Paraibano.

Mapa de localização dos empreendimentos com EIA/RIMA na Mesorregião do Sertão Paraibano

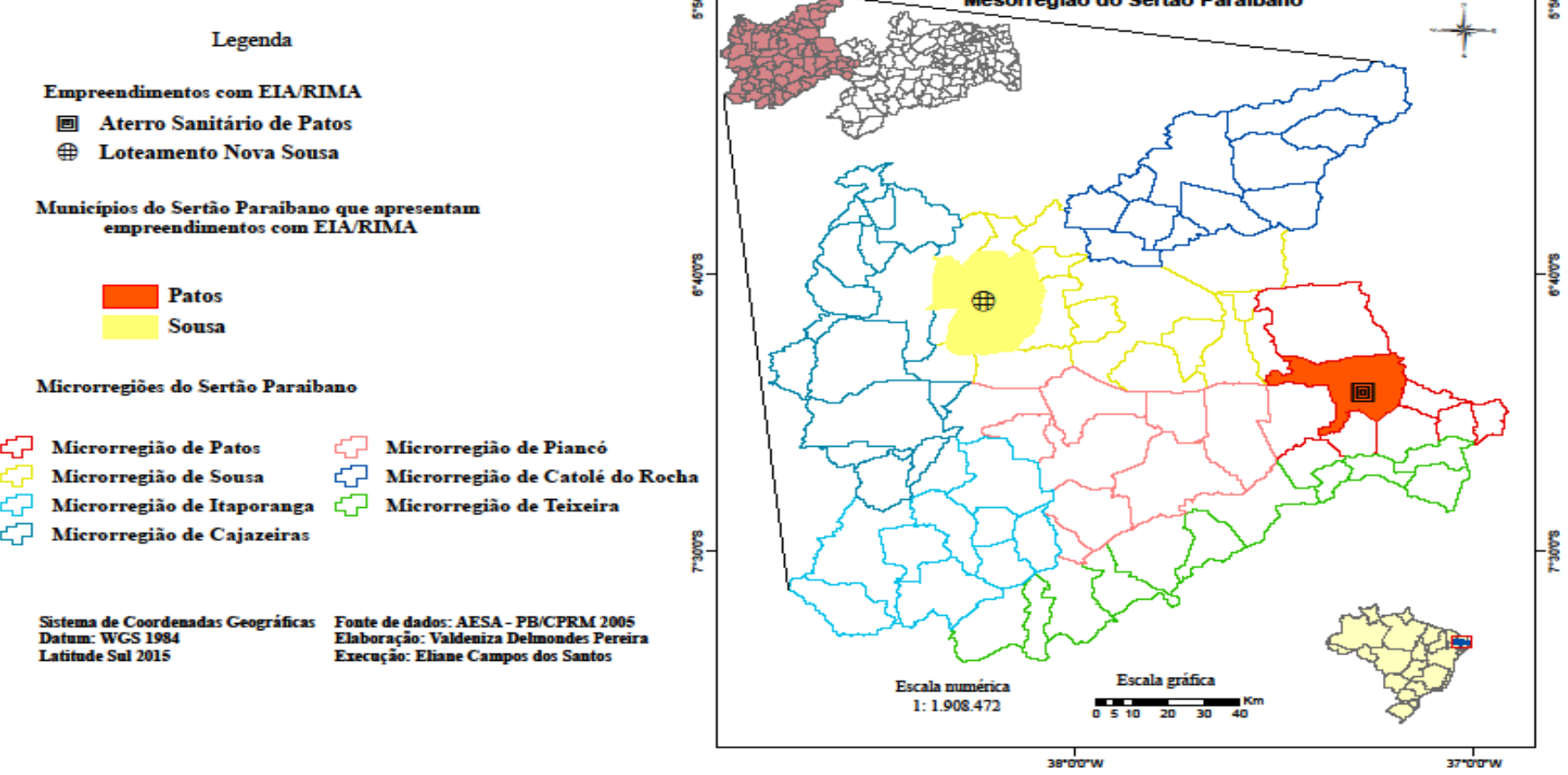

Os empreendimentos instalados nessa Mesorregião são da iniciativa privada, correspondendo a 6\% dos empreendimentos analisados: Aterro Sanitário de Patos, localizado na Microrregião de Patos e o Loteamento Nova Sousa, localizado na Microrregião de Sousa. Alguns fatores podem contribuir para a não instalação dos grandes empreendimentos nessa região: a distância dos maiores centros consumidores e rodovias em pior estado de conservação, dificultando o fluxo de mercadorias, além da baixa densidade populacional observada em algumas partes do território da mesorregião.

\section{CONCLUSÕES}

Os resultados demonstram que a maior parte dos empreendimentos/atividades que demandaram EIA/RIMA para serem licenciados no período de 2003 a 2014, estão localizados na mesorregião da Mata Paraibana. Pode-se inferir que essa grande concentração, especialmente na microrregião de João Pessoa, que apresenta $66 \%$ dos empreendimentos, está relacionada ao fato de ser o município de João Pessoa um importante polo irradiador da 
dinâmica regional, além de ser uma região densamente povoada, apresentando melhor infraestrutura urbana e desenvolvimento econômico superior às demais regiões paraibanas, o que confirma a ocorrência da prática da seletividade espacial. Em termos de concentração de empreendimentos, a Mesorregião do Agreste ficou em segundo lugar, apresentando $18 \%$ dos empreendimentos analisados no período. Esse resultado também pode ser reflexo da dinâmica nessa região em virtude de possuir grande densidade demográfica, especialmente na Microrregião de Campina Grande, onde estão localizados $83 \%$ dos empreendimentos dessa Mesorregião.

A maneira como os dados foram apresentados permite uma ampliação da visão acerca da configuração do licenciamento ambiental na Paraíba, possibilitando identificar os ramos de atividade dos empreendimentos e caracterizá-los, além de mapear a distribuição dos mesmos. Tal mapeamento demonstra que tanto características físicas, biológicas e/ou socioeconômicas influenciam na localização desses empreendimentos/atividades. Dessa forma, as áreas de maior desenvolvimento econômico e com as maiores densidades demográficas apresentaram o maior número de empreendimentos licenciados com EIA/RIMA na realidade do estado da Paraíba.

\section{REFERÊNCIAS}

BARBIERI, J. C. Gestão ambiental empresarial: conceitos, métodos e instrumentos. 2. ed. São Paulo: Saraiva, 2007.

BRASIL. MINISTÉRIO PÚBLICO FEDERAL. Deficiências em estudos de impacto ambiental: síntese de uma experiência. Brasília: Escola Superior do Ministério Público, 2004. BRASIL. Resolução CONAMA nº 001, de 23 de janeiro de 1986. Disponível em: < http://www.mma.gov.br/port/conama/res/res86/res0186.html >. Acesso em: 10.12.2017.

BRASIL. Resolução CONAMA n 237, de 19 de dezembro de 1997. Disponível em: <http://www.mma.gov.br/port/conama/res/res97/res23797.html>. Acesso em: 23.02.2018.

BRASIL. IBGE Cidades. Censo Demográfico 2010. Disponível em:< http://www.cidades.ibge.gov.br/xtras/uf.php?lang=\&coduf=25\&search=paraiba $>$. Acesso em: 04.11.2017.

CARVALHO, D. F. Desenvolvimento sustentável e seus limites teórico-metodológicos. In: FERNANDES, M.; GUERRA, L. (Org). Contra-discurso do desenvolvimento sustentável. Belém: Associação de Universidades Amazônicas, 2003. p. 197-234. 
CORRÊA, R. L. Corporações, práticas espaciais e gestão do território. Revista Brasileira de Geografia, Rio de Janeiro, v.54, n.3, p. 115-121, jul./set..1992.

CORRÊA, R. L. Região e organização espacial. 8. ed. São Paulo: Ática, 2007.

DANTAS, E. M.; MORAES, I. R. D. Organização do espaço. 2. ed. Natal: EDUFRNEditora da UFRN, 2012. 244 p.

FELICIANO, M. de L. M.; MELO, R. B. de. Atlas do Estado da Paraíba: Informação para Gestão do Patrimônio Natural. 1. ed. João Pessoa: SEPLAN/IDEME, 2003.

GUTIERRES, H.E.P.; SANTOS, C. J. da S.; RODRIGUES, J. de O. N.; PEREIRA, V. D. A abordagem geomorfológica nos Estudos de Impacto Ambiental: a realidade do estado da Paraíba entre os anos de 2005 e 2014. In: SILVA, A. B. da; GUTIERRES, H.E.P.; GALVÃO, J. de C. Paraíba: pluralidade e representações geográficas 2. Campina Grande: EDUFCG, 2017, 53-72.

HAESBAERT, R. Morte e vida da região: antigos paradigmas e novas perspectivas da geografia regional. In: SPOSITO, E. S. (org.). Produção do espaço e redefinições regionais: a construção de uma temática. Presidente Prudente: UNESP/FCT/GAsPERR, 2005.

HOOKE, J. M. Geomorphology in Environmental Planning. Plymouth, John Wiley and Sons Ltd., 1988.

LIMONAD. E. Urbanização e organização do espaço na era dos fluxos. In: SANTOS, M.; BECKER, B. K. et al (Orgs.). Território, territórios: ensaio sobre o ordenamento territorial. 3 ed. Rio de Janeiro: Lamparina, 2007. p. 145- 170.

MILARÉ, E.; BENJAMIM, A. H. V. A principiologia do estudo prévio de impacto ambiental e o controle da discricionariedade administrativa. In: MILARÉ, E.; BENJAMIM, A. H. V. Estudo prévio de impacto ambiental: teoria, prática e legislação. São Paulo: Editora Revista dos Tribunais, 1993. p. 63-124.

PAES, H. G. Contribuições da Geografia ao licenciamento e ao estudo de impacto ambiental. 2010. 148 f. Dissertação (Mestrado em Geografia). Universidade de São Paulo, São Paulo.

PEREIRA, V.D. Uma abordagem geográfica dos EIAs/RIMAs no estado da Paraíba. Monografia (Bacharelado em Geografia) - Departamento de Geociências, Universidade Federal da Paraíba, João Pessoa, 2015. 
PERIS, A. F.; LUGNANI, A. C. Um estudo sobre o eixo Cascavel - Foz do Iguaçu, na região Oeste do Paraná. Revista paranaense de desenvolvimento, Curitiba, n. 104, p. 79- 102, jan./jun. 2003.

RIBEIRO, H. Estudo de impacto ambiental como instrumento de planejamento. In: JR, A. P.; ROMÉRIO, M. de A.; BRUNA, G. C. (editores). Curso de gestão ambiental. Coleção ambiental 1. Barueri: Manole, 2004.

ROCHA, A. P. B.; OLIVEIRA, M. S. de. Geografia regional do Brasil. 2. ed. Natal: EDUFRN-Editora da UFRN, 2011. 310 p.

SANCHEZ, L. H. Avaliação de impacto ambiental: conceitos e métodos. 2. ed. São Paulo: Oficina de Textos, 2013.

SANTOS, M. A natureza do espaço: técnica e tempo, espaço e razão. São Paulo: EDUSP, 2002.

TEIXEIRA, M. G. et al. Análise dos Relatórios de Impactos Ambientais de Grandes Hidrelétricas no Brasil. In: AB'SABER, A. N.; MÜLLER-PLANTEMBERG, C.; (orgs.). Previsão de Impactos: O estudo de impacto ambiental no Leste, Oeste e Sul. Experiências no Brasil, na Rússia e na Alemanha. 2. ed. 2. reimp. São Paulo: Editora da Universidade de São Paulo, 2006. 